\title{
COMMENTARY
}

\section{The role of the StAR protein in steroidogenesis: challenges for the future}

\author{
D M Stocco \\ Department of Cell Biology and Biochemistry, Texas Tech University Health Sciences Center, Lubbock, Texas 79430, USA \\ (Requests for offprints should be addressed to D M Stocco; Email: doug.stocco@ttmc.ttuhsc.edu)
}

\begin{abstract}
The steroidogenic acute regulatory or StAR protein has been shown to be instrumental in the acute regulation of steroid hormone biosynthesis through its action in mediating cholesterol transfer to the inner mitochondrial membrane and the cholesterol side chain cleavage enzyme system. Since the time of its cloning in 1994, a number of studies have been performed which underscore the important role that this protein plays in steroidogenesis. While it is now quite apparent that StAR fulfills the criteria for the acute regulator as proposed by early studies, several crucial areas remain poorly understood. This list is
\end{abstract}

topped by the so far intractable nature of the mechanism of action of StAR in transferring cholesterol to the P450scc enzyme. A second area which should prove to be of great interest is that of further understanding the regulation of the StAR gene which, like many genes, is quite complex. Lastly, with the recent demonstration of StAR being present in the brain, determining if StAR has a role in the synthesis of neurosteroids should prove to be of great importance.

Journal of Endocrinology (2000) 164, 247-253

\section{Introduction}

Steroid hormones are synthesized in the adrenals, gonads, placenta and central nervous system. Different steroid hormones having different physiological effects arise from this synthesis, their nature being dependent on the array of enzymes present in the steroidogenic tissue in question. Regardless of tissue origin, however, a common feature of all steroid hormones is that their synthesis utilizes a common precursor, namely, cholesterol. In fact, it is the delivery of cholesterol to the site of its first enzymatic conversion that constitutes the rate-limiting and hormonally regulated step in steroidogenesis (Karaboyas \& Koritz 1965, Brownie et al. 1972, Simpson et al. 1979, Crivello \& Jefcoate 1980, Privalle et al. 1983, Jefcoate et al. 1987). In general terms, cellular cholesterol residing in the outer mitochondrial membrane, lipid droplets or plasma membranes of steroidogenic cells, must be delivered to the inner mitochondrial membrane, the site of the cytochrome P450 side chain cleavage enzyme (P450scc) which converts cholesterol to pregnenolone, the first steroid formed in all steroidogenic tissues. This delivery of cholesterol to the P450scc was determined to be an assisted process, and one that required de novo protein synthesis (Ferguson 1962, 1963, Garren et al. 1965, 1966).
The identity of the putative acute regulator protein remained a mystery for almost four decades. Although several candidate proteins were proposed, it now appears that the steroidogenic acute regulatory or StAR protein has emerged as the best candidate to fulfill this role. First identified as a $30 \mathrm{kDa}$ phosphoprotein associated with the mitochondria (Krueger \& Orme-Johnson 1983, Pon et al. 1986, Pon \& Orme-Johnson 1988, Stocco \& Kilgore 1988, Epstein \& Orme-Johnson 1991, Stocco \& Sodeman 1991), StAR was purified, cloned, sequenced and expressed in 1994 (Clark et al. 1994). Importantly, its expression in MA-10 or COS-1 cells resulted in significant increases in steroid hormone synthesis in the absence of hormone stimulation, thus indicating that StAR could mediate cholesterol transport to the P450scc enzyme (Clark et al. 1994, Sugawara et al. 1995, Lin et al. 1995, Stocco \& Clark 1996). Perhaps the most compelling evidence for the indispensable role for StAR in mediating cholesterol transfer and hence regulating steroid hormone biosynthesis was the finding that mutations in the StAR gene result in the potentially lethal condition known as congenital lipoid adrenal hyperplasia (Lin et al. 1995). This disease is characterized by an almost complete blockage of steroid hormone synthesis and significantly, this blockage was found to be at the locus of cholesterol delivery to the P450scc enzyme. 
More recently, StAR knockout mice have been generated and their phenotype is essentially identical to that seen in the human condition, further demonstrating the role for StAR in steroidogenesis (Caron et al. 1997b).

In the past five years, many studies have demonstrated the role of StAR in developmentally and hormonally regulated steroid biosynthesis. A number of previous review articles are available on this subject and more thoroughly summarize studies performed to date (Stocco \& Clark 1996, 1997, Stocco 1997a, b, 1998a, 1998b, 1999, Clark \& Stocco 1997, Miller 1997, 1998, Cherradi et al. 1998). The subject of this short review will be to point out what are, in the opinion of this author, several of the most challenging questions that have emerged concerning the role of StAR in steroidogenic tissues. This list is certainly not meant to imply that other areas are not of interest or importance, but is merely intended to delineate several problem areas that should be of interest to a variety of scientists.

\section{How does StAR transfer cholesterol?}

Clearly StAR has an indispensable function in the acutely regulated synthesis of steroids. How does it work? A model was proposed indicating that StAR was synthesized in the cytosol in response to trophic hormone stimulation, and during import into the mitochondrial inner compartment, contact sites between the inner and outer membranes were formed which served as the conduit for outer mitochondrial membrane cholesterol to transfer to the inner membrane (Epstein \& Orme-Johnson 1991, Stocco \& Sodeman 1991, Jefcoate et al. 1992, Stocco \& Clark 1996). It was soon clear that this model was incorrect. N-terminal truncations of the StAR protein that removed as many as 62 amino acids and completely inhibited import had no effect on cholesterol transfer or steroid production when transfected into MA-10 or COS-1 cells (Arakane et al. 1996, Wang et al. 1998). Similar observations were made in a completely in vitro system by Arakane et al. (1998) who demonstrated that bacterially produced StAR protein lacking the first $62 \mathrm{~N}$-terminal amino acids was able to support full steroidogenesis in isolated mitochondria but was not imported. Conversely, when mitochondria were incubated with StAR protein whose C-terminus was truncated by 28 amino acids, a complete loss of steroid production resulted (Arakane et al. 1996, Wang et al. 1998). These data all indicate that the C-terminal region of the StAR protein functions in cholesterol transfer.

A further indication of the importance of the $\mathrm{C}$-terminal region of the StAR protein in cholesterol transfer was shown by Watari et al. (1997), in describing the steroidogenic properties of a protein, MLN64, which has homology to the C-terminal region of StAR. Expression of MLN64 in COS-1 cells resulted in a twofold increase in steroid production. The relationship between StAR and MLN64 as well as the role of MLN64 in the cell remain to be determined and hopefully useful information concerning sterol movement in the cell will be obtained.

More recent studies have demonstrated that StAR can act as a sterol transfer protein to enhance sterol desorption from one membrane to another (Kallen et al. 1998a). In this model, StAR is directed to the mitochondria via its $\mathrm{N}$-terminus and then, via C-terminal sequences it produces alterations in the outer mitochondrial membrane that results in the transfer of cholesterol from the outer to the inner membrane. This transfer of cholesterol was specific in that identical experiments employing phosphatidylcholine failed to show transfer of this phospholipid. This is pertinent to the situation found in steroidogenic mitochondria in which the desorption of cholesterol from the sterol-rich outer membrane to the sterol-poor inner membrane (Martinez \& Strauss 1997) would serve to enhance pregnenolone synthesis by the P450scc enzyme (Kallen et al. 1998a).

While the mechanism of action of the StAR protein is still unknown, it seems clear that cholesterol transfer requires that it interact, at least transiently, with components such as proteins, lipids and/or other factors on the outside of the outer mitochondrial membrane and produce alterations which result in cholesterol transfer. The identification of such factors has so far proven to be quite elusive (Kallen et al. 1998b), but it appears that StAR promotes cholesterol transfer as a result of its direct interaction with the outer surface of the mitochondria and not through an intermediary (Kallen et al. 1998a). This was demonstrated through the use of recombinant StAR protein which, when added directly to purified mitochondria, was shown to increase pregnenolone production. To date, studies designed to identify StARinteracting proteins have utilized the yeast two-hybrid assay system with StAR as bait, co-immunoprecipitation of StAR expressing COS cell lysates and binding assays using radiolabeled StAR protein incubated with isolated mitochondria (Kallen et al. 1998b). None of these approaches has yet identified a legitimate StAR binding partner. Perhaps, as recently speculated (Arakane et al. 1998), StAR can stimulate cholesterol transfer, either as a result of a few very high affinity stable interactions with the outer mitochondrial membrane which are difficult to detect because of their low number, or as a result of transient interactions which would also be difficult to detect because of their fleeting nature. To determine how the StAR protein might interact with the outer mitochondrial membrane, Miller and colleagues subjected StAR to limited proteolysis at different $\mathrm{pH}$ values and found that the molecule behaves very differently as the $\mathrm{pH}$ decreases (Bose et al. 1999). They showed that StAR can form a molten globule in the $\mathrm{pH} 3 \cdot 5-4 \cdot 0$ range. i.e. if the $\mathrm{pH}$ microenvironment surrounding the mitochondria is acidic, the StAR molecule may undergo a conformational shift, forming an extended structure and increasing the flexibility of the linker region located between the 


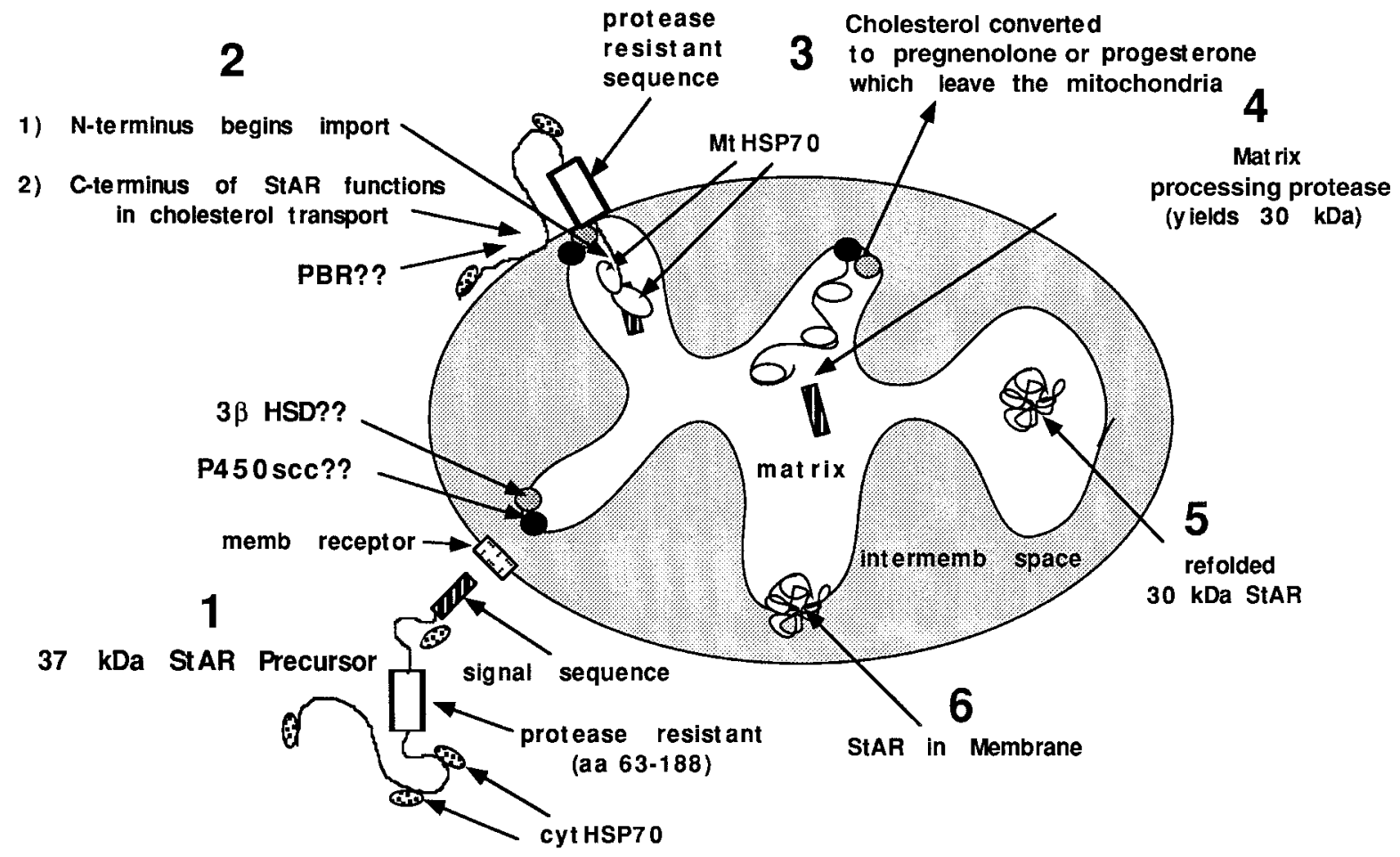

Figure 1 Putative mechanism of StAR action: The model in this figure represents what is currently known about the mechanism of action of StAR. (1) Upon stimulation of the steroidogenic cell with trophic hormone, the $37 \mathrm{kDa}$ StAR protein precursor is rapidly synthesized in the cytoplasm. This precursor is accompanied by chaperone proteins which prohibit folding of the precursor, a condition which would make import of the protein into the mitochondrion impossible. It is also noteworthy that a section of the protein encompassing amino acids 63-188 has been shown to be protease resistant, a feature which may be important in cholesterol transfer. (2) The $37 \mathrm{kDa}$ protein then becomes associated with the mitochondria and the import and processing of the precursor protein begins. At some point, either prior to the start of import, or simultaneously with it, sequences in the C-terminal portion of the StAR protein interact with as yet unidentified components of the outer mitochondrial membrane and result in cholesterol transfer to the inner mitochondrial membrane. The protease resistant portion of the StAR protein results in the formation of a molten globule which may be instrumental in cholesterol transfer. (3) Cholesterol is quickly converted to pregnenolone and in some steroidogenic tissues, to progesterone. (4) Cleavage of the precursor protein by the matrix processing protease results in the formation of the mature $30 \mathrm{kDa}$ form of the StAR protein. (5) StAR is refolded. (6) It becomes associated with the inner mitochondrial membrane and also with the intermembrane space. Once imported StAR is no longer in contact with the outer membrane and further transfer of cholesterol is stopped. Thus, it is the continuous synthesis and processing of precursor StAR to mature StAR, with the continual interaction between the C-terminal part of StAR and the outer mitochondrial membrane which is responsible for cholesterol transfer. Also, it is unknown as to whether or not the $30 \mathrm{kDa}$ form of the protein has any functional role when in the mitochondria. The nature of the components with which StAR interacts on the outer membrane are unknown, and perhaps the peripheral benzodiazepine receptor (PBR) is involved at this site. Also, the mitochondrial contact sites and inner membranes are enriched with the first two enzymes in the steroidogenic pathway, namely P450scc and $3 \beta$ hydroxysteroid dehydrogenase, raising the interesting possibility that cholesterol entering the mitochondria may leave as progesterone and not pregnenolone in at least some steroidogenic cell types.

N-terminus and the biologically active C-terminus while acting on the outer mitochondrial membrane. As the transition to a molten globule occurs, this structural change may lower the energy required to open the StAR structure further, possibly exposing a cholesterol channel or, it may prolong the interval in which StAR can reside on the outer membrane thus allowing increased transfer of cholesterol during this period.

Very little is known about the manner in which StAR effects cholesterol transfer to the inner mitochondrial membrane. Identification of the components interacting with StAR on the outer mitochondrial membrane and the nature of this interaction become of critical importance in understanding its mechanism of action. The identification of these putative binding partners has remained elusive and their characterization and the description of their role in cholesterol transfer can be considered as perhaps the most interesting and important undertaking in this field. A highly simplified illustration of what is currently known concerning the mechanism of action of StAR in transferring cholesterol from the outer to the inner mitochondrial membrane is shown in Fig. 1. 


\section{Regulation of the StAR gene}

The trophic hormone-induced increase in steroid production in steroidogenic cells is accompanied by rapid increases in StAR mRNA levels (Clark et al. 1995, Sugawara et al. 1995, Caron et al. 1997a). Since this is generally considered to be a cAMP-mediated event, attention focused on the role of cAMP in the regulation of the StAR gene (Caron et al. 1997a, Sugawara et al. 1995, 1996, 1997, Rust et al. 1998, Sandhoff et al. 1998, LaVoie et al. 1999). Like several other cAMP-regulated genes involved in steroid biosynthesis, the promoter region of the StAR gene lacks an easily recognizable cAMP response element. However, studies have shown that the cAMP responsive site is retained within a 245 nucleotide region relative to the transcription start site (Caron et al. 1997a). Therefore, this region has been the focus of studies to identify promoter elements and their cognate-binding proteins that could mediate the cAMP response.

A transcription factor considered to be potentially important in the regulation of the StAR gene was steroidogenic factor 1 (SF-1). SF-1 was first identified in adrenal cortical cells, and has been shown to be instrumental in regulating the cytochrome P450 steroid hydroxylase genes (Ikeda et al. 1993). Of special interest to studies on StAR function was the finding that SF-1 knockout mice do not express StAR mRNA, indicating that SF-1 is required for proper StAR gene expression (Caron et al. 1997a). Several SF-1 consensus binding sites have been found in the StAR promoter. In rats, five SF-1 sites have been reported (Sandhoff et al. 1998), and one additional site has been identified in humans and mice (Caron et al. 1997a, Sugawara et al. 1997). Two of these sites, which are located at positions -97 and -42 , are highly conserved in several species whose promoter regions have been sequenced to date. Most importantly, SF-1 has been demonstrated to transactivate the StAR promoter in transient transfection assays in numerous cell types (Caron et al. 1997a, Sugawara et al. 1996, 1997, Sandhoff et al. 1998). SF-1 may also play some role in the developmental regulation of the StAR gene as StAR mRNA is not detected in the urogenital ridge of SF-1 null mice (Caron et al. 1997b).

While SF-1 was shown to participate in StAR expression, it was apparent that additional elements were involved in StAR's tissue and temporal specific expression, and the search for additional transacting factors and/or co-regulators involved in the regulation of the StAR gene has begun. The CCAAT/enhancer binding proteins (C/EBPs), are a family of basic region/leucine zipper transcription factors implicated as regulators of differentiation and function of multiple cell types (Johnson \& Williams 1994). Previous studies have demonstrated that family members $\mathrm{C} / \mathrm{EBP} \alpha$ and $\mathrm{C} / \mathrm{EBP} \beta$ are expressed in Leydig cells and ovarian granulosa cells (Nalbant et al. 1998, Sirois \& Richards 1993). We recently identified two
$\mathrm{C} / \mathrm{EBP}$ binding sites in the StAR promoter of MA-10 Leydig cells in our laboratory (Reinhart et al. 1999). We also determined that the StAR promoter is transactivated by $\mathrm{C} / \mathrm{EBP} \beta$ and that SF-1 transactivation of the StAR promoter is dependent on the presence of functional $\mathrm{C} / \mathrm{EBP}$ binding sites, suggesting that SF-1 and C/EBP $\beta$ form a complex on this promoter. Silverman et al. (1999) recently conducted functional assays of the StAR promoter using follicle-stimulating hormone (FSH) induced naive primary granulosa cells from prepubertal rat ovaries. This approach led to the identification of a non-consensus binding sequence for $\mathrm{C} / \mathrm{EBP} \beta(-81 /-72)$, located just ten nucleotides upstream from a consensus motif for GATA-4 binding (-61/-66). Site-directed mutagenesis of both binding sites essentially eliminated basal and hormone driven StAR expression, reinforcing the notion that both of these elements are required for FSH-induced acute transactivation of the StAR promoter in these cells. Western blot analyses showed that GATA-4 is constitutively expressed in granulosa cells whereas three isoforms of $\mathrm{C} / \mathrm{EBP} \beta$ were rapidly induced by FSH. Therefore, it was suggested that while GATA-4 may play a permissive role, C/EBP $\beta$ could meet the criteria of a transcription factor which could regulate acute StAR transcription in granulosa cells. In another recent study, it has been demonstrated that the sterol regulatory element binding protein (SREBP) may also be involved in the regulation of the StAR gene as it was reported that SREBP-1a was capable of transactivating the StAR promoter (Christenson et al. 1998). While no consensus binding sites for SREBP-1a have yet been found in the StAR promoter, this may prove to be an example of the convergence of the regulation of cholesterol metabolism and steroidogenesis. It should be noted that while the transcription factors SF-1, C/EBP $\beta$, GATA-4 and SREBP-1a have all been shown to be active in StAR gene expression, the absolute requirements for acute regulation have not yet been fully determined.

In summary, knowledge regarding the regulation of the StAR gene is expanding rapidly and it has become quite apparent that, like many other genes, a host of transcription factors and/or co-regulators are involved in its expression. Since it is becoming abundantly clear that regulation of the StAR gene is a complex process, the biggest challenge in this area will be to characterize those elements that are involved in its acute regulation and those that serve to provide tissue-specific and temporal-specific expression of the gene. Figure 2 depicts a comparison of the promoter region of five different species in which this region has been sequenced. As is readily seen, sequence homology has been highly conserved in several areas of the StAR promoter.

\section{StAR in the brain}

Like the highly active steroidogenic tissues, the adrenal gland and the gonads, the central and peripheral nervous 

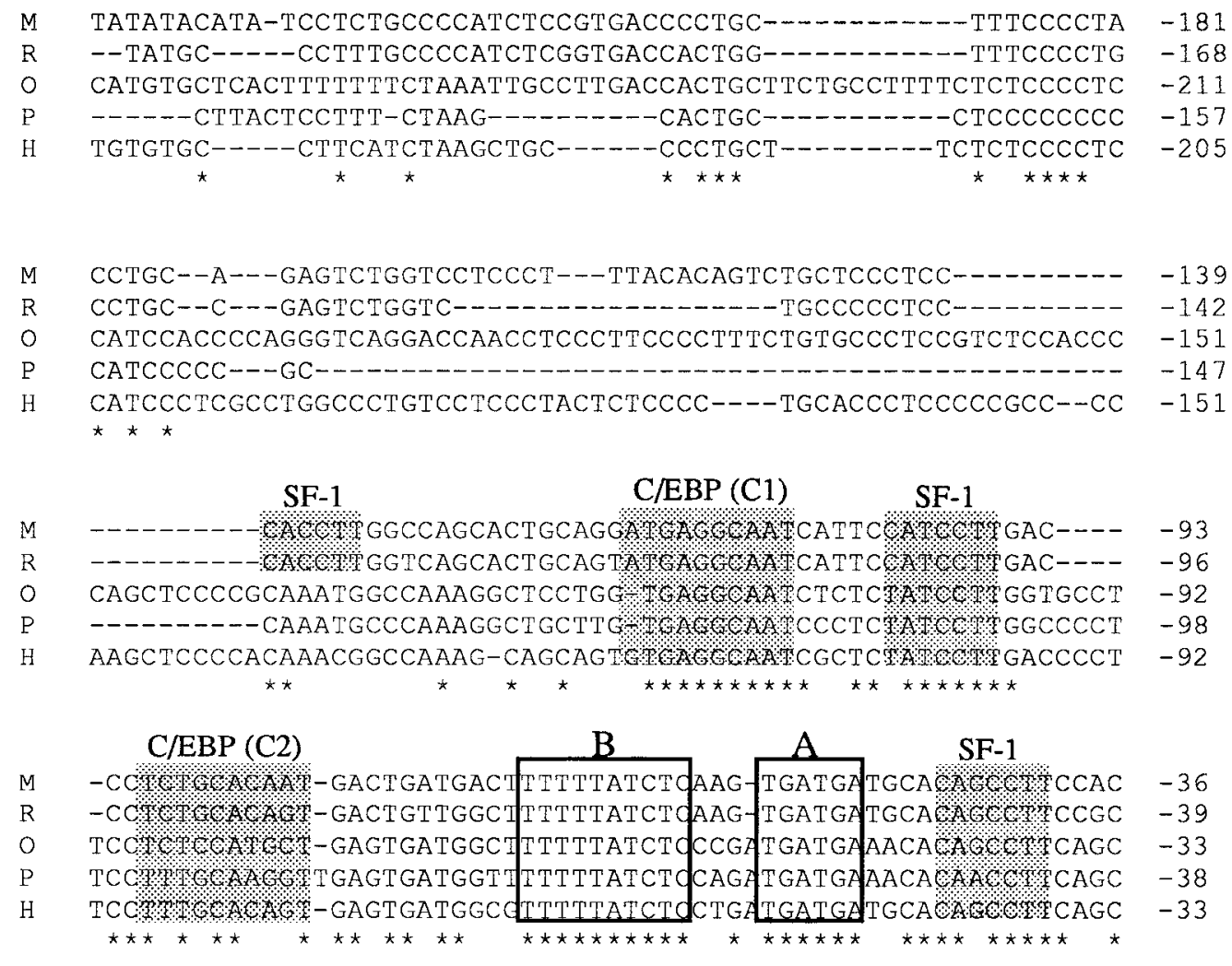

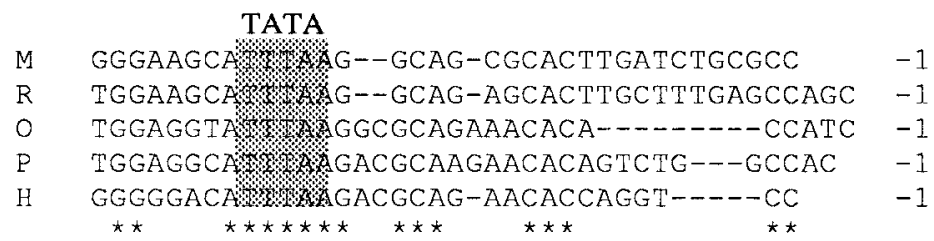

Figure 2 StAR promoter comparisons: Comparison of the sequences of the $5^{\prime}$ flanking regions of the mouse $(\mathrm{M})$, rat $(\mathrm{R})$, ovine $(\mathrm{O})$, porcine $(\mathrm{P})$, and human $(\mathrm{H})$ StAR genes were aligned using the ClustalW sequence alignment program and identical bases in all five sequences are indicated with asterisks. Binding sites for SF-1 are shaded and labeled. Two putative C/EBP binding sites were identified based on their similarity to the consensus C/EBP binding site and are shaded and labeled. Other highly conserved sequences discussed in the text are boxed and labeled $\mathrm{A}$ and $\mathrm{B}$.

systems also synthesize steroids, which are collectively referred to as neurosteroids (Baulieu 1997). The neurosteroids exhibit a number of physiological functions which include both stimulation and inhibition of GABAergic responses (Majewska et al. 1986), modulation of the response of Purkunje cells to excitatory amino acids (Smith 1991) and enhancement of memory function (Flood et al. 1992, Mathis et al. 1994). The nature of neurosteroid biosynthesis and certainly the mechanisms involved in its regulation are not, however, well understood. Given the purported role of StAR in steroidogenesis, it was of great interest to determine if it was present in central nervous tissue. The first reports detailing the localization of StAR in human and mouse tissues failed to detect its presence in brain (Clark et al. 1995, Sugawara et al. 1995). Thus it remained unclear if StAR performed any role in neurosteroid synthesis. It could perhaps be predicted that if StAR were found in the brain, it would be present at much lower levels, given the highly reduced nature of neurosteroid synthesis when compared with adrenals and gonads. Using the sensitive method of RT-PCR, Furukawa et al. (1998) have demonstrated that StAR transcripts are indeed present in rat brain, an observation which was confirmed with in situ hybridization techniques. StAR transcripts were present in the cerebral cortex, hippocampus, dentate gyrus, olfactory bulb, cerebral granular layer and Purkinje cells. These investigators estimated that the amount of StAR transcripts 
present in the brain was two to three orders of magnitude less than that found in the adrenal gland, hence the difficulty in their detection by less sensitive methods. These investigators were also able to demonstrate that StAR transcripts were co-expressed with cytochrome P450scc and 3 $3-\mathrm{HSD}$ in the hippocampus, dentate gyrus, cerebral granular layer and Purkinje cells. These results indicate that neurosteroids are synthesized in highly specific regions in the brain and that the StAR protein may be involved in this synthesis. A great deal more work must be performed to make definitive statements on the characteristics of neurosteroid synthesis and the potential role of StAR in this synthesis, but the demonstration that StAR is co-localized with steroidogenic pathway enzymes in the brain should make this an exciting area of study in the future. For example, it will be possible to determine if the StAR knockout mouse suffers from any central nervous system deficiencies. Also, the particularly provocative question of whether or not StAR, and perhaps neurosteroid synthesis, is regulated in the brain can now be addressed.

\section{Acknowledgements}

The author would like to acknowledge the support of NIH grant HD 17481 during the course of these studies.

\section{References}

Arakane F, Sugawara T, Nishino H, Liu Z, Holt HA, Pain D, Stocco DM, Miller WL \& Strauss III JF 1996 Steroidogenic acute regulatory protein (StAR) retains activity in the absence of its mitochondrial import sequence: Implications for the mechanism of StAR action. Proceedings of the National Academy of Sciences $\mathbf{9 3}$ 13731-13736.

Arakane F, Kallen CB, Watari H, Foster JA, Sepuri NBV, Pain D, Stayrook SE, Lewis M, Gerton GL \& Strauss III JF 1998 The mechanism of action of steroidogenic acute regulatory protein (StAR): StAR acts on the outside of mitochondria to stimulate steroidogenesis. Journal of Biological Chemistry 273 16339-16345.

Baulieu EE 1997 Neurosteroids: Of the nervous system, by the nervous system, for the nervous system. Recent Progress in Hormone Research 52 1-32.

Bose HS, Whitall RM, Baldwin MA \& Miller WL 1999 The active form of the steroidogenic acute regulatory protein, StAR, appears to be a molten globule. Proceedings of the National Academy of Sciences of the USA 96 7250-7255.

Brownie AC, Simpson ER, Jefcoate CR, Boyd GS, Orme-Johnson WH \& Beinert H 1972 Effect of ACTH on cholesterol side-chain cleavage in rat adrenal mitochondria. Biochemical and Biophysical Research Communications 46 483-490.

Caron KM, Ikeda Y, Soo SC, Stocco DM, Parker KL \& Clark BJ $1997 a$ Characterization of the promoter region of the mouse gene encoding the steroidogenic acute regulatory (StAR) protein. Molecular Endocrinology 11 136-147.

Caron KM, Soo SC, Wetsel WC, Stocco DM, Clark BJ \& Parker KL $1997 b$ Targeted disruption of the mouse gene encoding steroidogenic acute regulatory protein provides insights into congenital lipoid adrenal hyperplasia. Proceedings of the National Academy of Sciences of the USA 94 11540-11545.
Cherradi N, Brandenburger Y \& Capponi AM 1998 Mitochondrial regulation of mineralocorticoid biosynthesis by calcium and the StAR protein. European Journal of Endocrinology 139 249-256.

Christenson LK, McAllister JM, Martin KO, Javitt NB, Osborne TF \& Strauss III JF 1998 Oxysterol regulation of steroidogenic acute regulatory protein gene expression: structural specificity and transcriptional and postranslational actions. Journal of Biological Chemistry 273 30729-30735.

Clark BJ \& Stocco DM 1997 Steroidogenic acute regulatory protein. The StAR still shines brightly. Molecular and Cellular Endocrinology $1341-8$.

Clark BJ, Wells J, King SR \& Stocco DM 1994 The purification, cloning, and expression of a novel LH-induced mitochondrial protein in MA-10 mouse Leydig tumor cells: characterization of the steroidogenic acute regulatory protein (StAR). Journal of Biological Chemistry $26928314-28322$.

Clark BJ, Soo SC, Caron KM, Ikeda Y, Parker KL \& Stocco DM 1995 Hormonal and developmental regulation of the steroidogenic acute regulatory (StAR) protein. Molecular Endocrinology 9 1346-1355.

Crivello JF \& Jefcoate CR 1980 Intracellular movement of cholesterol in rat adrenal cells. Journal of Biological Chemistry 255 8144-8151.

Epstein LF \& Orme-Johnson NR 1991 Regulation of steroid hormone biosynthesis: Identification of precursors of a phosphoprotein targeted to the mitochondrion in stimulated rat adrenal cortex cells. Journal of Biological Chemistry 266 19739-19745.

Ferguson JJ 1962 Puromycin and adrenal responsiveness to adrenocorticotropic hormone. Biochimica et Biophysica Acta $\mathbf{5 7}$ 616-617.

Ferguson JJ 1963 Protein synthesis and adrenocorticotropin responsiveness. Journal of Biological Chemistry 238 2754-2759.

Flood JF, Morley JE \& Roberts E 1992 Memory enhancing effects in male mice of pregnenolone and steroids metabolically derived from it. Proceedings of the National Academy of Sciences of the USA $\mathbf{7 8}$ 4704-4707.

Furukawa A, Miyatake A, Ohnishi T \& Ichikawa Y 1998 Steroidogenic acute regulatory protein (StAR) transcripts constitutively expressed in the adult rat central nervous system: colocalization of StAR, cytochrome P-450scc (CYP X1A1), and $3 \beta$-hydroxysteroid dehydrogenase in the rat brain. Journal of Neurochemistry 71 2231-2238.

Garren LD, Ney RL \& Davis WW 1965 Studies on the role of protein synthesis in the regulation of corticosterone production by ACTH in vivo. Proceedings of the National Academy of Sciences of the USA 53 1443-1450.

Garren LD, Davis WW \& Crocco RM 1966 Puromycin analogs: action of adrenocorticotropic hormone and the role of glycogen. Science 152 1386-1388.

Ikeda Y, Lala DS, Luo X, Kim E, Moisan MP \& Parker KL 1993 Characterization of the mouse FTZ-F1 gene, which encodes a key regulator of steroid hydroxylase gene expression. Molecular Endocrinology 7 852-860.

Jefcoate CR, DiBartolomeos MJ, Williams CA \& McNamara BC 1987 ACTH regulation of cholesterol movement in isolated adrenal cells. Journal of Steroid Biochemistry and Molecular Biology 27 721-729.

Jefcoate CR, McNamara BC, Artemenko I \& Yamazaki T 1992 Regulation of cholesterol movement to mitochondrial cytochrome $\mathrm{P} 450 \mathrm{scc}$ in steroid hormone synthesis. Journal of Steroid Biochemistry and Molecular Biology 43 751-767.

Johnson PF \& Williams SC 1994 CCAAT/Enhancer binding (C/EBP) proteins. In Liver Gene Expression pp 231-258. Eds F Tronch \& M Yaniv. Austin, TX, USA: Landes Company.

Kallen CB, Billheimer JT, Summers SA, Staybrook SE, Lewis M \& Strauss III JF 1998a Steroidogenic acute regulatory protein (StAR) is a sterol transfer protein. Journal of Biological Chemistry 273 $26285-26288$. 
Kallen CB, Arakane F, Christenson LK, Watari H, Devoto L \& Strauss III JF $1998 b$ Unveiling the mechanism of action and regulation of the steroidogenic acute regulatory protein. Molecular and Cellular Endocrinology 145 39-45.

Karaboyas GC \& Koritz SB 1965 Identity of the site of action of cAMP and ACTH in corticosteroidogenesis in rat adrenal and beef adrenal cortex slices. Biochemistry 4 462-468.

Krueger RJ \& Orme-Johnson NR 1983 Acute adrenocorticotropic hormone stimulation of adrenal corticosteroidogenesis. Journal of Biological Chemistry 258 10159-10167.

LaVoie H, Garmey JC \& Veldhuis JD 1999 Mechanisms of insulin-like growth factor-1 augmentation of follicle-stimulating hormone-induced porcine steroidogenic acute regulatory protein promoter activity in granulosa cells. Endocrinology 140 146-153.

Lin D, Sugawara T, Strauss III JF, Clark BJ, Stocco DM, Saenger P, Rogol A \& Miller WL 1995 Role of steroidogenic acute regulatory protein in adrenal and gonadal steroidogenesis. Science $\mathbf{2 6 7}$ 1828-1831.

Majewsksa MD, Harrison NL \& Schwartz RD 1986 Steroid hormone metabolites are barbiturate-like modulators of the GABA receptor. Science 232 1004-1007.

Martinez F \& Strauss III JF 1997 Regulation of mitochondrial cholesterol metabolism. In Subcellular Biochemistry. Cholesterol: Its Functions and Metabolism in Biology and Medicine vol 28, pp 205-234. Ed. R Bittman. New York: Plenum Press.

Mathis C, Paul SM \& Crawley J 1994 The neurosteroid pregnenolone sulfate blocks NMDA antagonist-induced deficits in a passive avoidance memory task. Psychopharmacology 116 201-206.

Miller WL 1997 Congenital lipoid adrenal hyperplasia: The human gene knockout of the steroidogenic acute regulatory protein. Journal of Molecular Endocrinology 19 227-240.

Miller WL 1998 Lessons from congenital lipoid adrenal hyperplasia. Current Opinion in Endocrinology and Diabetes 5 155-161.

Nalbant D, Williams SC, Stocco DM \& Khan SA 1998 Luteinizing hormone-dependent gene regulation in Leydig cells may be mediated by CCAAT/enhancer-binding protein-beta. Endocrinology 139 272-279.

Pon LA, Hartigan JA \& Orme-Johnson NR 1986 Acute ACTH regulation of adrenal corticosteroid biosynthesis: rapid accumulation of a phosphoprotein. Journal of Biological Chemistry 261 13309-13316.

Pon LA \& Orme-Johnson NR 1988 Acute stimulation of corpus luteum cells by gonadotropin or adenosine $3^{\prime} 5^{\prime}$-monophosphate causes accumulation of a phosphoprotein concurrent with acceleration of steroid synthesis. Endocrinology 123 1942-1948.

Privalle CT, Crivello J \& Jefcoate CR 1983 Regulation of intramitochondrial cholesterol transfer to side-chain cleavage cytochrome P450scc in rat adrenal gland. Proceedings of the National Academy of Sciences of the USA $\mathbf{8 0} 702-706$.

Reinhart AJ, Williams SC, Clark BJ \& Stocco DM 1999 SF-1 (Steroidogenic Factor 1) and C/EBP $\beta$ (CAAT Enhancer Binding Protein $\beta$ ) cooperate to regulate the murine StAR (Steroidogenic Acute Regulatory Protein) promoter. Molecular Endocrinology 13 729-741.

Rust W, Stedronsky K, Tillmann G, Morley S, Walther N \& Ivell R 1998 The role of SF-1/Ad4 BP in the control of the bovine gene for the steroidogenic acute regulatory (StAR) protein. Journal of Molecular Endocrinology 21 189-200.

Sandhoff TW, Hales DB, Hales KH \& McLean MP 1998 Transcriptional regulation of the rat steroidogenic acute regulatory protein gene by steroidogenic factor 1. Endocrinology 139 4820-4831.

Silverman E, Eimerl S \& Orly J 1999 C/EBP $\beta$ and GATA-4 binding regions within the promoter of the steroidogenic acute regulatory protein (StAR) gene are required for transcription in rat ovarian cells. Journal of Biological Chemistry 274 17987-17996.
Simpson ER, McCarthy JL \& Peterson JA 1979 Evidence that the cycloheximide-sensitive site of ACTH action is in the mitochondrion. Journal of Biological Chemistry 253 3135-3139.

Sirois J \& Richards JS 1993 Transcriptional regulation of the rat prostaglandin endoperoxide synthase 2 gene in granulosa cells. Evidence for the role of a cis-acting C/EBP beta promoter element. Journal of Biological Chemistry 268 21931-21938.

Smith SS 1991 Progesterone administration attenuates excitatory amino acid responses of cerebellar Purkinje cells. Neuroscience 42 309-320.

Stocco DM 1997a A StAR search: Implications in controlling steroidogenesis. Biology of Reproduction 56 328-336.

Stocco DM $1997 b$ The steroidogenic acute regulatory (StAR) protein two years later: an update. Endocrine 6 99-110.

Stocco DM 1998a A review of the characteristics of the protein required for the acute regulation of steroid hormone biosynthesis: the case for the steroidogenic acute regulatory (StAR) protein. Proceedings of the Society of Experimental Biology and Medicine 217 123-129.

Stocco DM 1998 Recent advances in the role of the steroidogenic acute regulatory (StAR) protein. Reviews of Reproduction 3 82-85.

Stocco DM 1999 Steroidogenic acute regulatory (StAR) protein. In Vitamins and Hormones, vol 55, pp 399-441. Ed. G Litwack. San Diego: Academic Press.

Stocco DM \& Kilgore MW 1988 Induction of mitochondrial proteins in MA-10 Leydig tumour cells with human choriogonadotropin. Biochemical Journal 249 95-103.

Stocco DM \& Sodeman TC 1991 The 30-kDa mitochondrial proteins induced by hormone stimulation in MA-10 mouse Leydig tumor cells are processed from larger precursors. Journal of Biological Chemistry 266 19731-19738.

Stocco DM \& Clark BJ 1996 Regulation of the acute production of steroids in steroidogenic cells. Endocrine Reviews 17 221-244.

Stocco DM \& Clark BJ 1997 The role of the steroidogenic acute regulatory protein in steroidogenesis. Steroids 62 29-36.

Sugawara T, Holt JA, Driscoll D, Strauss III JF, Lin D, Miller WL, Patterson D, Clancy KP, Hart IM, Clark BJ \& Stocco DM 1995 Human steroidogenic acute regulatory protein: functional activity in COS-1 cells, tissue-specific expression, and mapping of the gene to $8 \mathrm{p} 11.2$ and a pseudogene to chromosome 13. Proceedings of the National Academy of Sciences of the USA 92 4778-4782.

Sugawara T, Holt JA, Kiriakidou M \& Strauss III JF 1996 Steroidogenic factor 1-dependent promoter activity of the human steroidogenic acute regulatory protein (StAR) gene. Biochemistry 35 9052-9059.

Sugawara T, Kiriakidou M, McAllister JM, Kallen CB \& Strauss III JF 1997 Multiple steroidogenic factor 1 binding elements in the human steroidogenic acute regulatory protein gene $5^{\prime}$-flanking region are required for maximal promoter activity and cyclic AMP responsiveness. Biochemistry 36 7249-7255.

Wang XJ, Liu Z, Eimerl S, Weiss AM, Orly J \& Stocco DM 1998 Effect of truncated forms of the steroidogenic acute regulatory (StAR) protein on intramitochondrial cholesterol transfer. Endocrinology 139 3903-3912.

Watari H, Arakane F, Moog-Lutz C, Kallen CB, Tomasetto C, Gerton GL, Rio M, Baker ME \& Strauss III JF 1997 MLN64 contains a domain with homology to the steroidogenic acute regulatory protein (StAR) that stimulates steroidogenesis. Proceedings of the National Academy of Sciences 94 8462-8467.

Received 29 July 1999

Accepted 23 September 1999 